\title{
Preparation of Dräger Atlan A350 and General Electric Healthcare Carestation 650 anesthesia workstations for malignant hyperthermia susceptible patients
}

\author{
Sebastian Heiderich ${ }^{1 *} \mathbb{0}$, Christian Thoben², Nils Dennhardt ${ }^{1} \mathbb{B}$, Terence Krauß ${ }^{1}$, Robert Sümpelmann ${ }^{1} \mathbb{0}$,
} Stefan Zimmermann ${ }^{2}$, Michael Reitz ${ }^{1}$ and Henrik Rüffert ${ }^{3}$

\begin{abstract}
Background: Patients at risk of malignant hyperthermia need trigger-free anesthesia. Therefore, anesthesia machines prepared for safe use in predisposed patients should be free of volatile anesthetics. The washout time depends on the composition of rubber and plastic in the anesthesia machine. Therefore, new anesthesia machines should be evaluated regarding the safe preparation for trigger-free anesthesia. This study investigates wash out procedures of volatile anesthetics for two new anesthetic workstations: Dräger Atlan A350 and General Electric Healthcare (GE) Carestation 650 and compare it with preparation using activated charcoal filters (ACF).

Methods: A Dräger Atlan and a Carestation 650 were contaminated with $4 \%$ sevoflurane for $90 \mathrm{~min}$. The machines were decontaminated with method (M1): using ACF, method 2 (M2): a wash out method that included exchange of internal parts, breathing circuits and soda lime canister followed by ventilating a test lung using a preliminary protocol provided by Dräger or method 3 (M3): a universal wash out instruction of $\mathrm{GE}$, method 4 (M4): M3 plus exchange of breathing system and bellows. Decontamination was followed by a simulated trigger-free ventilation. All experiments were repeated with $8 \%$ desflurane contaminated machines. Volatile anesthetics were detected with a closed gas loop high-resolution ion mobility spectrometer with gas chromatographic pre-separation attached to the bacterial filter of the breathing circuits. Primary outcome was time until $<5 \mathrm{ppm}$ of volatile anesthetics and total preparation time.

Results: Time to $<5 \mathrm{ppm}$ for the Atlan was $17 \mathrm{~min}$ (desflurane) and $50 \mathrm{~min}$ (sevoflurane), wash out continued for a total of $60 \mathrm{~min}$ according to protocol resulting in a total preparation time of $96-122 \mathrm{~min}$. The Carestation needed $66 \mathrm{~min}$ (desflurane) and $24 \mathrm{~min}$ (sevoflurane) which could be abbreviated to $24 \mathrm{~min}$ (desflurane) if breathing system and bellows were changed. Total preparation time was 30-73 min. When using active charcoal filters time to $<5 \mathrm{ppm}$ was 0 min for both machines, and total preparation time $<5$ min.
\end{abstract}

Conclusion: Both wash out protocols resulted in a significant reduction of trace gas concentrations. However, due to the complexity of the protocols and prolonged total preparation time, feasibility in clinical practice remains questionable. Especially when time is limited preparation of the anesthetic machines using ACF remain superior.

Keywords: Malignant hyperthermia, Trigger-free anesthesia, Patient safety, Volatile anesthetics, Succinylcholine

*Correspondence: heiderich.sebastian@mh-hannover.de

${ }^{1}$ Clinic of Anaesthesiology and Intensive Care Medicine, Hannover

Medical School, Carl-Neuberg-Str. 1, 30625 Hannover, Germany

Full list of author information is available at the end of the article

(c) The Author(s) 2021. Open Access This article is licensed under a Creative Commons Attribution 4.0 International License, which permits use, sharing, adaptation, distribution and reproduction in any medium or format, as long as you give appropriate credit to the original author(s) and the source, provide a link to the Creative Commons licence, and indicate if changes were made. The images or other third party material in this article are included in the article's Creative Commons licence, unless indicated otherwise in a credit line to the material. If material is not included in the article's Creative Commons licence and your intended use is not permitted by statutory regulation or exceeds the permitted use, you will need to obtain permission directly from the copyright holder. To view a copy of this licence, visit http://creativecommons.org/licenses/by/4.0/. The Creative Commons Public Domain Dedication waiver (http://creativeco mmons.org/publicdomain/zero/1.0/) applies to the data made available in this article, unless otherwise stated in a credit line to the data. 


\section{Introduction}

Malignant hyperthermia (MH) is an inherited pharmaco-genetic disorder in which affected individuals are at risk to develop life-threatening metabolic crises when in contact to volatile anesthetics and/or succinylcholine. Whenever patients with a known susceptibility to malignant hyperthermia (MHS), or patients with $\mathrm{MH}$ associated myopathies (central core disease, KingDenborough syndrome and some other rare muscle disorders) need anesthesia, either regional or so called "trigger-free" general anesthesia is recommended. This includes, that the anesthetic machine should be clean of residual volatile anesthetics. Unfortunately, cleaning modern anesthetic machines highly differs from manufacturer and device because volatile anesthetics adsorb and desorb to different amount of rubber and plastic components of the anesthetic machine [1]. The European Malignant Hyperthermia Group (EMHG) have developed consensus guidelines on perioperative management of MHS patients that contains recommendations on the elimination of residual trace concentrations of volatile anesthetics in the machine to ensure a trigger-free anesthesia [2]. Basically, three different approaches are recommended: First: Using a spare anesthetic machine which had never contact to any volatile anesthetic. Second: Using activated charcoal filters (ACF) to eliminate trace gas concentrations. Third: Preparing the anesthetic machines by washing out volatile anesthetics according to manufacturer's instructions of the device. The first two approaches can be less cost effective depending on the circumstances (operation room workload and estimated number of triggerfree anesthesia per year) [3]. Regarding the wash out method, most manufacturer does not give approved instructions how to wash out the volatile anesthetics from the anesthetic machines. In the literature most anesthetic machines are evaluated regarding the preparation process for trigger-free anesthesia $[1,3-5]$. The EMHG guidelines provide an overview of the known wash out times for most anesthesia machines, but data is missing for the newest generation devices. Therefore, this study aims to investigate wash out profiles of the Dräger Atlan 350 and General Electric Healthcare (GE) Carestation 650. There are no official instructions available for both machines yet. However, we used a preliminary wash out protocol from Dräger and a general instruction from GE in which the steps are standardized for all devices varying only by the wash out time needed for each machine series [6]. This study should help clinicians to decide which approach to trigger-free anesthesia is most practicable and economic for their individual hospital.

\section{Methods}

\section{Contamination phase}

A test lung was ventilated with $8 \%$ desflurane or $4 \%$ sevoflurane for $90 \mathrm{~min}$ using the Autoflow Mode (AF) of the Atlan A350, and Pressure Control VentilationVolume Guaranteed (PCV-VG) of the Carestation 650. Other settings were as following: FGF of $41 \cdot \mathrm{min}^{-1}$, tidal volume $500 \mathrm{~mL}$, respiratory rate 12 breaths $/ \mathrm{min}$ ute, positive end-expiratory pressure (PEEP) $5 \mathrm{mbar}$, inspired to expired time ratio of 1:1.9 for the Atlan A350 and 1:2 for the Carestation 650. The high concentrations of volatile anesthetics were chosen to create rather heavily contaminated machines with the intention to set up a worst-case scenario. Therefore, the anesthetic machines were contaminated with the same contamination method as previously reported [7].

\section{Preparation methods}

After contamination phase different methods were used to clean the machines from volatile anesthetics. Each method was tested separately on sevoflurane and desflurane contaminated machines. The preparation methods are shown more in detail in Table 1. The preparation was conducted together by two anesthetic consultants (authors S. H and T.K.).

\section{Active charcoal filter procedure}

Method 1 (M1): Both anesthetic machines were also prepared using ACF: The Vaporizer was turned off, manual mode was selected, APL ventil turned to zero (Spont), a FGF of $101 \cdot \mathrm{min}^{-1}$ was selected for $90 \mathrm{~s}$. After that, activated charcoal filters were inserted to both the inspiratory and expiratory limb. Subsequently, breathing circuits, breathing bag, bacterial filter, $\mathrm{CO}_{2}$ sampling line, sodium lime canister and test lung was changed. This procedure was taken from the manufacturer instructions (https://www.dynastheti cs.com/Vapor-Clean/Vapor-Clean-IFU.pdf). M1 was performed four times: on a sevoflurane contaminated Atlan A350, desflurane contaminated Atlan A350, sevoflurane contaminated Carestation 650 and desflurane contaminated Carestation 650.

\section{Atlan A350 procedure}

Method 2 (M2): A preliminary draft protocol of the Dräger company was used to clean the machine: This included vapor removal, change of breathing circuits, breathing bag, bacterial filter, $\mathrm{CO}_{2}$ sampling line, sodium lime canister, water trap, breathing system and breathing membrane. The protocol included a $60 \mathrm{~min}$ ventilation of a test lung at a FGF of $15 \mathrm{l} \cdot \mathrm{min}^{-1}$. 


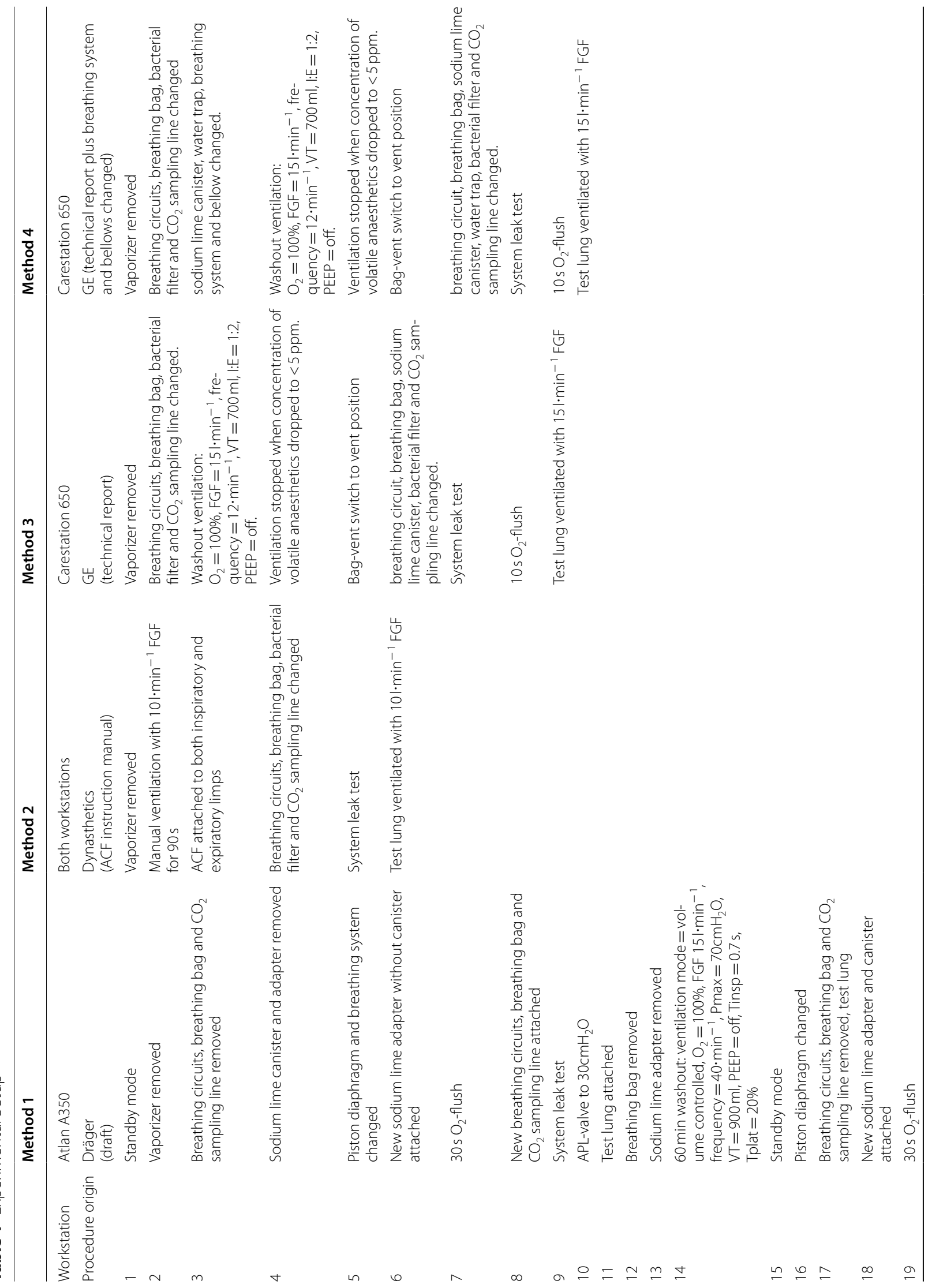




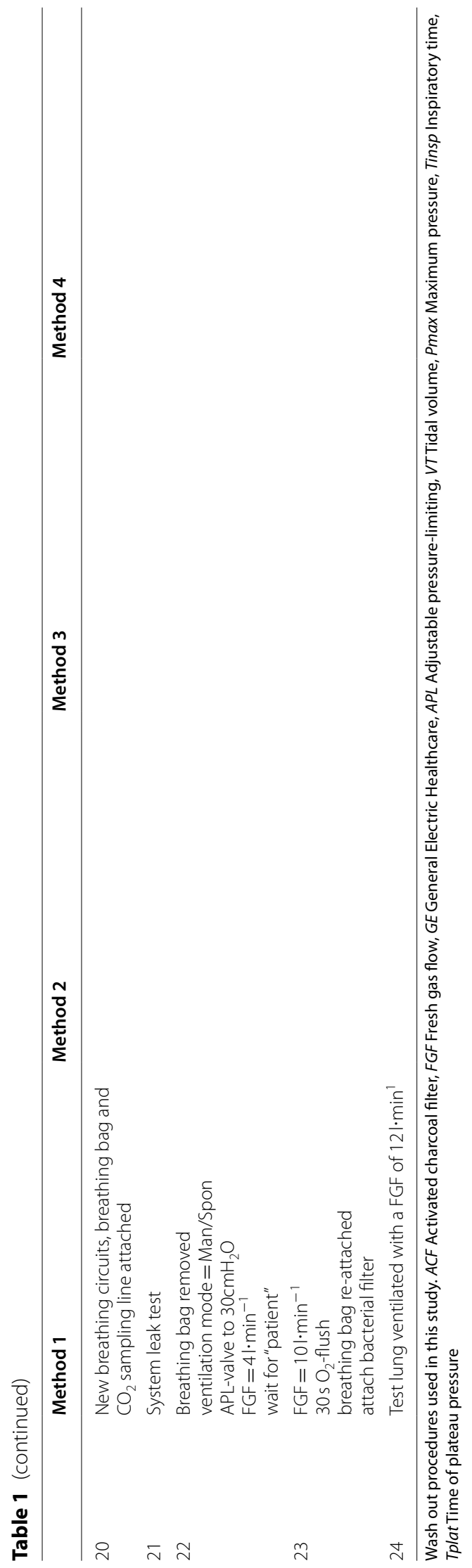


M2 was performed on one sevoflurane contaminated machine and one desflurane contaminated machine.

\section{Carestation 650 procedure}

Method 3 (M3): Preparation according to universal manufacturer's instructions [6]. First, the vaporizer was removed. Then breathing circuits, breathing bag, bacterial filter, $\mathrm{CO}_{2}$ sampling line and test lung was changed. $\mathrm{A}$ system leak test was performed. After that, the test lung was ventilated using PCV-VG Mode, FGF $151 \cdot \mathrm{min}^{-1}$, tidal volume $700 \mathrm{~mL}$, respiratory rate of 12 breaths/minute, inspired to expired time ratio of 1:2 with no PEEP. As no data on the washout time is available for the Carestation 650 , the ventilation was continued until the volatile anesthetic dropped to $<5 \mathrm{ppm}$. After that, the bag-vent switch set to vent position. After that breathing circuits, breathing bag, bacterial filter, $\mathrm{CO}_{2}$ sampling line, sodium lime canister and test lung was changed. The $\mathrm{O}_{2}$ flush was activated for $10 \mathrm{~s}$. After that the preparation was finished and the experiment continued with "waiting for the simulated patient". M3 was performed on one sevoflurane and one desflurane contaminated machine.

Method 4 (M4): Like M3 plus an additional change of breathing system and bellows with autoclaved spare parts at the beginning of the preparation. Also, the water trap and soda lime canister both were changed twice: in the beginning and at the end of the preparation.

A preparation with active charcoal filters was also carried out for the Carestation (see M2). M4 was performed on one sevoflurane and one desflurane contaminated machine.

\section{Waiting for the simulated patient and trigger-free ventilation}

After the preparation process a simulated waiting time for the patient was set to $20 \mathrm{~min}$ where the machines were set to manual mode with a FGF of $41 \cdot \mathrm{min}^{-1}$. Then, a new test lung was ventilated for $20 \mathrm{~min}$ using the same ventilation settings as during the contamination phase.

The FGF during the simulation was chosen in accordance with manufacturer's instructions:

Dynasthetics: M1: $31 \cdot \mathrm{min}^{-1}$.

Dräger: $\mathrm{M} 2: 121 \cdot \mathrm{min}^{-1}$ (double minute volume). GE: M3, M4: $151 \cdot \mathrm{min}^{-1}$.

After that, a rebound phenomenon was provoked: In experiments M1 the ACF were removed, and ventilation was continued with $31 \cdot \mathrm{min}^{-1}$ FGF. In experiments $\mathrm{M} 2$, M3 and M4 ventilation was continued using a reduced FGF of $11 \cdot \mathrm{min}^{-1}$. This was chosen to reveal residual contamination of the machines. It is not recommended to do this in clinical practice.

\section{Main outcome measures}

For both anesthetic machines, the washout time of desflurane and sevoflurane was measured. It was defined as the time needed from start of the test-lung ventilation to the reduction of inspiratory volatile anesthetic gas concentration $<5 \mathrm{ppm}$. Also, the total preparation time for each method was logged. It was defined as the time needed for the whole procedure from the beginning of the preparation until the machine was ready for triggerfree ventilation, that included assembling and dissembling of the equipment.

\section{Ion mobility spectrometry}

In all experiments, a high-resolution $\left(R_{P}=90\right)$ ion mobility spectrometer (IMS) with gas chromatographic preseparation (GC) operated with a closed gas loop is used to determine the concentrations of volatile anesthetics. The GC-IMS was developed by Leibniz University Hannover. In ion mobility spectrometry analyte molecules are first ionized and subsequently identified by their ion mobility in a so-called drift gas under the influence of an electric field. IMS provide highest sensitivity and detection limits in the low parts per billion ( $\mathrm{ppb}$ ) and even parts per trillion (ppt) range in less than a second of measuring time. Today, even highest resolution can be reached [8]. However, in this study the measured concentrations are far above the detection limit. Brief details relevant to this study are given here; a detailed description of the system and its applications can be found elsewhere [9-11]. A $10 \mathrm{~m}$ standard capillary column (Restek, RTX volatiles, ID $530 \mu \mathrm{m}$, film thickness $2 \mu \mathrm{m}$ ) at a constant temperature of $\mathrm{T}=50^{\circ} \mathrm{C}$ is used as $\mathrm{GC}$ column. The sample loop volume is just $10 \mu \mathrm{l}$, due to the high sensitivity of the IMS and the high concentrations of the volatile anesthetics. During operation, the sample loop is flushed by a defined gas flow of $50 \mathrm{ml} \cdot \mathrm{min}^{-1}$ from the sample inlet which was connected to the bacterial filter via a gas sample line. The sample loop volume is injected via a 6-port-valve into the GC carrier gas stream with a carrier gas flow of $5 \mathrm{ml} \cdot \mathrm{min}^{-1}$, resulting in a GC run time of $60 \mathrm{~s}$. Thus, all peaks found in GC-IMS measurements are characterized by their ion mobility, GC retention time and peak area, which relates to the compound concentration. The GC-IMS was calibrated with homemade permeation tubes using a Vici Dynacalibrator Model 150 permeation oven.

\section{Results \\ Atlan A350}

When using ACF (M1) the concentrations of volatile anesthetics immediately dropped to $<1 \mathrm{ppm}$ for desflurane and $<2.5 \mathrm{ppm}$ for sevoflurane and remained there 
during simulated trigger-free ventilation until the ACF were removed: A rebound of up to $80 \mathrm{ppm}$ desflurane and $50 \mathrm{ppm}$ sevoflurane was observed. The wash out time of M2 was $17 \mathrm{~min}$ in the desflurane experiment and $50 \mathrm{~min}$ in the sevoflurane experiment. In both experiments wash out ventilation was continued for a total of $60 \mathrm{~min}$ as stated in the procedure protocol (see Table 1). During simulated trigger-free ventilation the concentrations remained below $5 \mathrm{ppm}$ in both the sevoflurane and desflurane experiments. A rebound effect was observed after the FGF was reduced to $11 \cdot \mathrm{min}^{-1}$ (see Fig. 1a, b). Total preparation time, which included assembling and dissembling of the equipment, was $<5 \mathrm{~min}$ for M1 and 96-122 min for M2.

\section{Carestation 650}

When using ACF (M1) the concentrations of volatile anesthetics immediately dropped to $<1 \mathrm{ppm}$ for desflurane and $<2 \mathrm{ppm}$ for sevoflurane and remained there during simulated trigger-free ventilation until the ACF were removed: A rebound of up to $25 \mathrm{ppm}$ desflurane and $73 \mathrm{ppm}$ sevoflurane was observed. The wash out time of M3 was $66 \mathrm{~min}$ in the desflurane experiment and $24 \mathrm{~min}$ in the sevoflurane experiment. Wash out ventilation was continued for a total of 72 and $86 \mathrm{~min}$ as no live information about the exact concentration was available with our detecting method used. During simulated trigger-free ventilation the concentrations remained below $5 \mathrm{ppm}$ in both the sevoflurane and desflurane experiments. A rebound effect was observed after the FGF was reduced to $11 \cdot \mathrm{min}^{-1}$ (See Fig. 2a, b). In M4 the concentrations dropped after $24 \mathrm{~min}$ to $<5 \mathrm{ppm}$ in both the sevoflurane and desflurane experiment. Wash out ventilation was continued for a total of 55 and $59 \mathrm{~min}$ as no live information about the exact concentration was available with our detecting method used. Rebound effects of $10 \mathrm{ppm}$ sevoflurane and $34 \mathrm{ppm}$ desflurane were recorded after reducing the FGF to $11 \cdot \mathrm{min}^{-1}$ (See Fig. 3a, b). Total preparation time was $<5 \mathrm{~min}$ (M1), 30-73 $\mathrm{min}$ (M3) and 31-37 min (M4).

\section{Discussion}

\section{Wash out time is not equal to preparation time}

The washout time of the Atlan A350 (M2) was $<60$ min and therefore shorter than similar products of the same manufacturer and comparable other anesthetic machines [1]. This might be due to the extensive protocol used in M2: all exchangeable parts were changed, including the breathing system. The breathing circuits and piston diaphragm were changed even twice. Unfortunately, this led to an extensive overall preparation time (96-122 $\mathrm{min}$ in this study) which would surely benefit from a training effect. Still, trigger-free ventilation is a rare need, and therefore any routine experience of the nurses and anesthesiologists may remain limited. Also, the vast number of steps in this protocol (see Table 1) may lead to noncompliance or mistakes and therefore seems not suitable in clinical practice. The desflurane washout time of the Carestation 650 (M3) was longer than other anesthetic machines from GE as described in their technical report [6]. This highlights the need to gain experimental data from every new machine. However, the prolonged
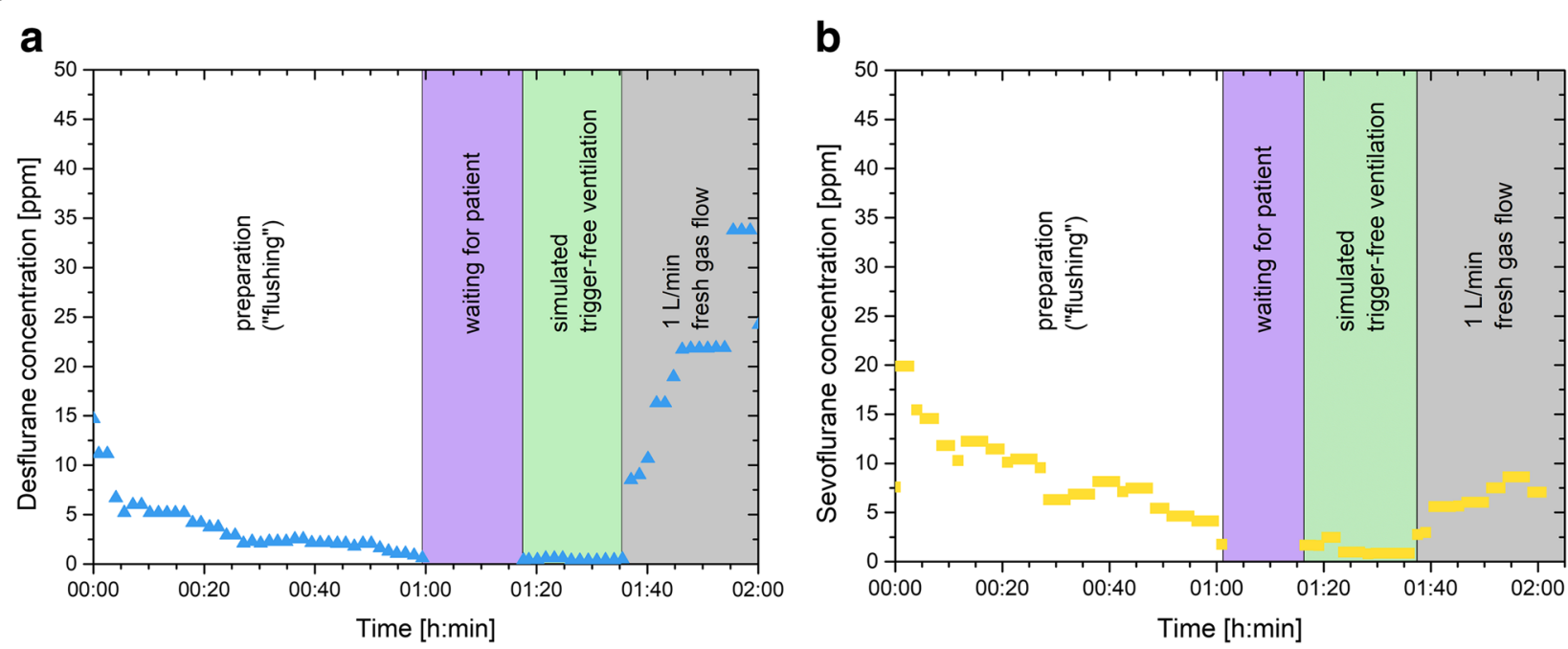

Fig. 1 Wash out procedure and simulated trigger-free ventilation of the Atlan A350 using manufacturer's protocol. Ppm; parts per million. During waiting time for the simulated patient, the machine was set to manual mode with a fresh gas flow of $4 \mid \cdot \mathrm{min}^{-1}$. A Desflurane experiment $\mathbf{B}$ Sevoflurane experiment 

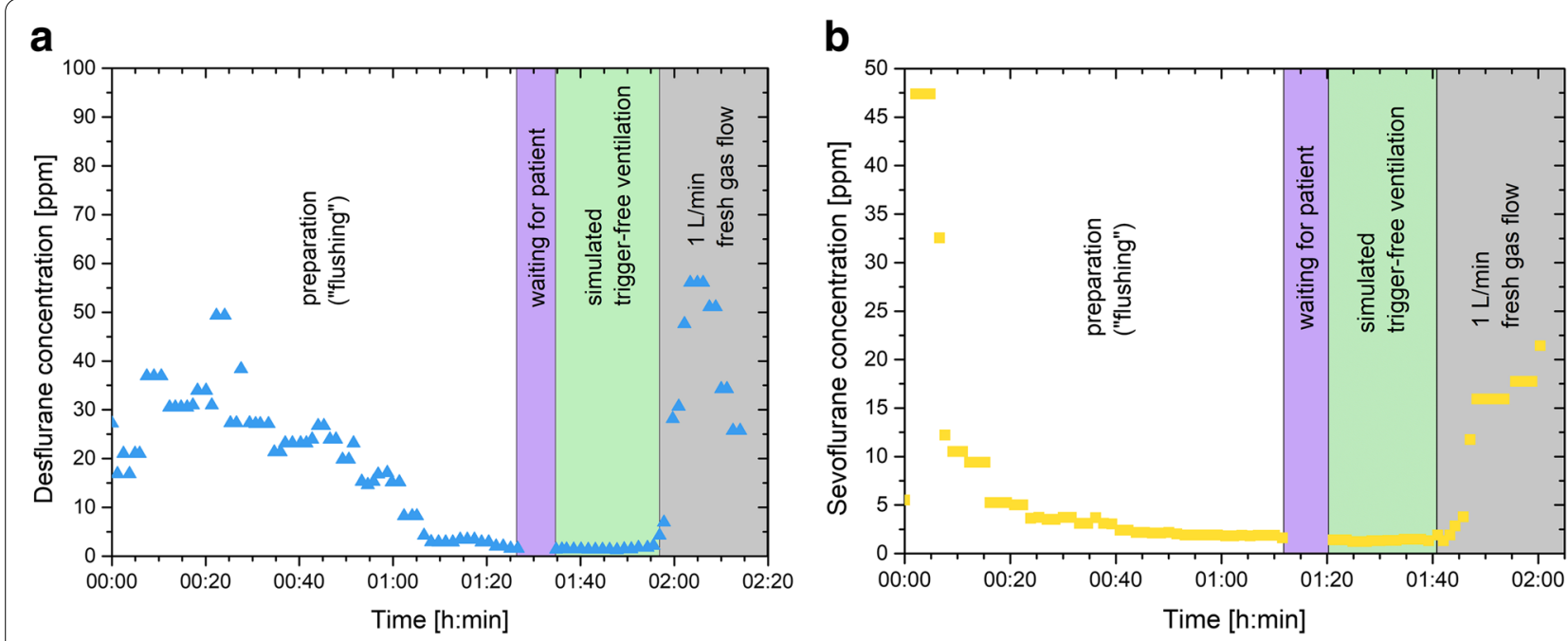

Fig. 2 Wash out procedure and simulated trigger-free ventilation of the Carestation 650 using manufacturer's protocol. Ppm; parts per million. During waiting time for the simulated patient, the machine was set to manual mode with a fresh gas flow of $4 \mid \cdot \mathrm{min}^{-1}$. A Desflurane experiment $\mathbf{B}$ Sevoflurane experiment
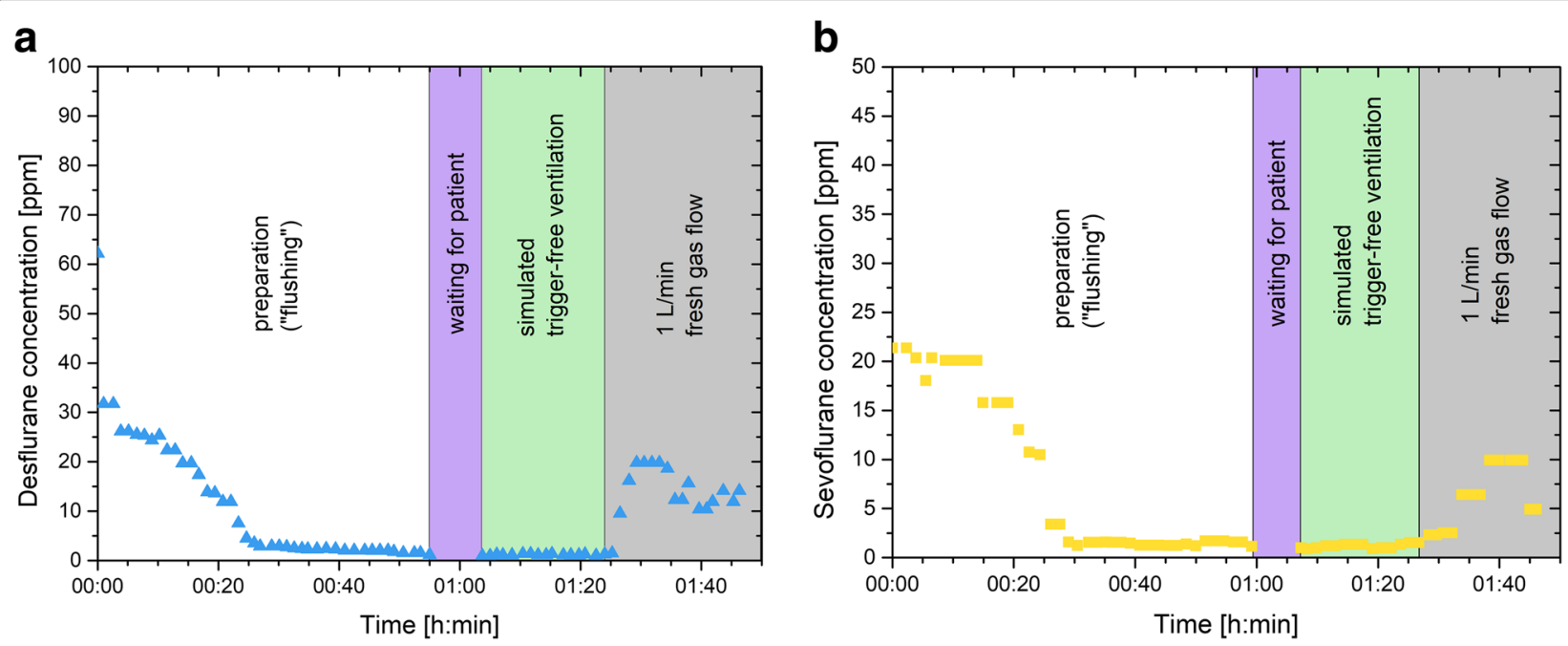

Fig. 3 Wash out procedure and simulated trigger-free ventilation of the Carestation 650 using manufacturer's protocol with surplus exchange of the breathing system and bellows. Ppm; parts per million. During waiting time for the simulated patient, the machine was set to manual mode with a fresh gas flow of $41 \cdot \mathrm{min}^{-1}$. A Desflurane experiment $\mathbf{B}$ Sevoflurane experiment

desflurane wash out time was shortened when the breathing system and bellows were changed (M4). This could be considered a feasible alternative method to clinicians.

\section{Active charcoal filters vs. wash out procedures}

Both the EMHG and the Malignant Hyperthermia Association of the United States (MHAUS) recommend using ACF (Vapor-Clean ${ }^{\mathrm{TM}}$, Dynasthetics, Salt Lake City, UT) as alternative method to prepare anesthetic machines for trigger-free anesthesia. The preparation with ACF (M1) was - not surprisingly - more user-friendly and less time consuming. Moreover, the absolute concentrations of volatile anesthetics were lower ( $<1 \mathrm{ppm})$ compared to the washout protocols of both machines. The advantage of the ACF lies in the simplicity (short and clear instruction checklist), speed (readiness within $5 \mathrm{~min}$ ) and universality for all different anesthetic machines. Therefore, in case of emergency surgery or reorganization of the operation schedule the ACF seems more practicable. The only disadvantage is the extra material costs ( $85 €$ in Germany). 
Still, in some circumstances (operation schedules with high workload) the use of ACF can be more cost efficient compared to wash out procedures when taking loss of operation time into account [3].

\section{Rebounds and fresh gas flow}

All experiments showed a relevant rebound effect after reduction of FGF, or removal of ACF respectively. This shows that both anesthetic machines are continuing to emit volatile anesthetics. Therefore, even after the washout procedure the machines must be considered as contaminated and any reduction of FGF or even short standby time should be avoided during trigger-free ventilation. This may be problematic in pediatric anesthesia, were a low FGF is recommended to avoid loss of heat and moisture. If using ACF, the filters should be remained in place for the whole anesthetic procedure [2]. The manufacturer recommend changing ACF after $12 \mathrm{~h}$, but in previews studies we demonstrated a safe use of the ACF for 24h [7].

\section{Limitations of the study \\ Repetition of the experiments}

In this study all experiments were only performed once per method, machine, and anesthetic gas. Different machines of the same type with different levels of contamination may result in different wash out time needed to get below $5 \mathrm{ppm}$.

\section{Hardware and software versions}

Deviations of the product series, software version and equipment may potentially affect the washout times of volatile anesthetics. The experiments were conducted using new machines previously used for demonstration on exhibitions. In clinical practice, anesthetic machines may show different levels of contamination after years of repetitive exposure to volatile anesthetics. Therefore, a rather high contamination (4\% sevoflurane and $8 \%$ desflurane) was chosen. Thereby, measurements were taken in a worst-case scenario to avoid false low wash out times.

\section{Material aging and contact time}

Both anesthetic machines include internal unchangeable rubber and plastic components. The material characteristics may change over the years. Plastic and rubber are known to become more porous over time which may lead to a different adsorption and desorption rates of volatile anesthetics. Therefore, the wash out times needed for old machines of the same type may differ from this experiment.

\section{Ventilation modes}

Both anesthetic machines are overly complex and the gas flow directions and speed inside the machines are depending on the ventilation mode in use. Therefore, conclusions may only be drawn in respect to the ventilation modes used in this study.

\section{Conclusion}

Current guidelines from EMGH and MHAUS recommending a concentration of $<5 \mathrm{ppm}$ of any volatile anesthetic during trigger-free anesthesia. If choosing a washout procedure to reach that goal, manufacturer's instructions should be used if available. The procedures are more complex than a simple flush for modern anesthetic machines. Therefore, total preparation time is longer than the washout time itself. This study showed that a preliminary washout procedure of Dräger meet the requirements of trigger-free anesthesia for the Atlan A350 in this study. Even though the time to $<5 \mathrm{ppm}$ were only $17 \mathrm{~min}$ (desflurane) and $50 \mathrm{~min}$ (sevoflurane) we still recommend conducting the full $60 \mathrm{~min}$ of wash out ventilation of the protocol, because contamination of the machines may vary as stated in our limitation section. In this study the general instructions of GE [6] were successfully used to prepare the Carestation 650. Here, the wash out times were $24 \mathrm{~min}$ (sevoflurane) and $66 \mathrm{~min}$ (desflurane), which could be shortened with an exchange of the breathing system and bellows to $24 \mathrm{~min}$. Because of the prolonged total preparation time in both machines and the complexity of the procedures the use of ACF is more feasible in clinical practice especially when time is critical. Future studies should further investigate rebound effects during trigger-free anesthesia, because in clinical practice ventilation modes and FGF rates are frequently changed during general anesthesia.

\footnotetext{
Abbreviations

ACF: Activated charcoal filters; AF: Autoflow Mode; APL: Adjustable pressurelimiting; EMHG: European Malignant Hyperthermia Group; FGF: Fresh gas flow; GC: Gas chromatographic pre-separation; GE: General Electric Healthcare; IMS: Ion mobility spectrometer; M1: Method 1; M2: Method 2; M3: Method 3; M4: Method 4; MAC: Minimum alveolar concentration; MH: Malignant hyperthermia; MHS: Malignant hyperthermia susceptible; MHAUS: Malignant Hyperthermia Association of the United States; PCV-VG: Pressure control ventilation-volume guaranteed; Pmax: Maximum pressure; ppb: Parts per billion; ppt: Parts per trillion; Tinsp: Inspiratory time; Tplat: Time of plateau pressure; VT:Tidal volume.
}

\section{Supplementary Information}

The online version contains supplementary material available at https://doi. org/10.1186/s12871-021-01533-0.

Additional file 1. 


\section{Acknowledgements \\ None.}

\section{Authors' contributions}

$\mathrm{SH}, \mathrm{CT}, \mathrm{ND}, \mathrm{TK}, \mathrm{SZ}, \mathrm{MR}$, RS and HR contributed to the study design, to collecting or analyzing data and drafting the manuscript. CT and SZ adjusted the GC-IMS prototype to the meet the requirements of this study. All authors have revised and approved the final version of the manuscript.

\section{Funding}

Open Access funding enabled and organized by Projekt DEAL. Dräger Germany and General Electric Healthcare Germany provided the anesthesia workstations. The companies did not influence the article in any way: No editing of the protocol, no financial support, no drug supply, no data analysis, and no writing of the paper.

\section{Availability of data and materials}

The datasets used and/or analyzed during the current study are available from the corresponding author on reasonable request.

\section{Declarations}

Ethics approval and consent to participate

As there were no humans or animals involved, no ethical approval was necessary for this laboratory technical study.

\section{Consent for publication}

Not applicable.

\section{Competing interests}

R. S. received fees for speeches and funds for research from B. Braun Melsungen AG, Melsungen, Germany. SH, CT, ND, TK, SZ, MR and HR have no conflicts of interests to declare.

\section{Author details}

${ }^{1}$ Clinic of Anaesthesiology and Intensive Care Medicine, Hannover Medical School, Carl-Neuberg-Str. 1, 30625 Hannover, Germany. ${ }^{2}$ Department of Sensors and Measurement Technology, Leibniz University Hannover, Institute of Electrical Engineering and Measurement Technology, Hannover, Germany. ${ }^{3}$ Clinic of Anaesthesiology and Intensive Care Medicine, Helios Klinik Schkeuditz, Leipzig, Germany.

Received: 20 July 2021 Accepted: 1 December 2021

Published online: 13 December 2021

\section{References}

1. Kim TW, Nemergut ME. Preparation of modern anesthesia workstations for malignant hyperthermia-susceptible patients: a review of past and present practice. Anesthesiology. 2011;114(1):205-12.

2. Rüffert H, Bastian B, Bendixen D, Girard T, Heiderich S, Hellblom A, et al. Consensus guidelines on perioperative management of malignant hyperthermia suspected or susceptible patients from the European malignant hyperthermia group. Br J Anaesth. 2021;126(1):120-30.

3. Neira VM, Al Madhoun W, Ghaffari K, Barrowman N, Berrigan P, Splinter W. Efficacy of malignant hyperthermia Association of the United StatesRecommended Methods of preparation for malignant hyperthermiasusceptible patients using Drager Zeus anesthesia workstations and associated costs. Anesth Analg. 2019;129(1):74-83.

4. Muller-Wirtz LM, Meiser A, Kermad A, Godsch C, Sessler DI, VolkT, et al. Response by the authors, reflection of volatile anesthetic by the vaporclean filter. Acta Anaesthesiol Scand. 2020;64(9):1383-4.

5. Cottron N, Larcher C, Sommet A, Fesseau R, Alacoque X, Minville V, et al. The sevoflurane washout profile of seven recent anesthesia workstations for malignant hyperthermia-susceptible adults and infants: a bench test study. Anesth Analg. 2014;1 19(1):67-75.

6. Kim T, Tham R. GE Healthcare non-clinical internal lab test report number DOC0994043; 2011.
7. Thoben C, Dennhardt N, Krauß T, Sümpelmann R, Zimmermann S, Rüffert $\mathrm{H}$, et al. Preparation of anaesthesia workstation for trigger-free anaesthesia: an observational laboratory study. Eur J Anaesthesiol. 2019;36(11):851-6.

8. Kirk AT, Bohnhorst A, Raddatz C-R, Allers M, Zimmermann S. Ultrahigh-resolution ion mobility spectrometry — current instrumentation, limitations, and future developments. Anal Bioanal Chem. 2019;411(24):6229-46.

9. Speckbacher V, Zeilinger S, Zimmermann S, Mayhew CA, Wiesenhofer $\mathrm{H}$, Ruzsanyi V. Monitoring the volatile language of fungi using gas chromatography-ion mobility spectrometry. Anal Bioanal Chem. 2021;413(11):3055-67.

10. Langejuergen J, Wagner C, Beutel S, Hopmeier T, Scheper T, Zimmermann S. Non-invasive monitoring of bacterial growth and auto-induced protein production in a bioreactor with a closed-loop GC-IMS. Int J Ion Mobil Spectrom. 2015;18(1-2):9-15.

11. Heiderich S, Thoben C, Dennhardt N, Koppert W, Krauß T, Sümpelmann $R$, et al. Low anaesthetic waste gas concentrations in postanaesthesia care unit: a prospective observational study. Eur J Anaesthesiol. 2018;35(7):534-8.

\section{Publisher's Note}

Springer Nature remains neutral with regard to jurisdictional claims in published maps and institutional affiliations.

Ready to submit your research? Choose BMC and benefit from:

- fast, convenient online submission

- thorough peer review by experienced researchers in your field

- rapid publication on acceptance

- support for research data, including large and complex data types

- gold Open Access which fosters wider collaboration and increased citations

- maximum visibility for your research: over $100 \mathrm{M}$ website views per year

At BMC, research is always in progress.

Learn more biomedcentral.com/submissions 